\title{
Swept source: optical coherence tomography angiography features of choroidal osteoma with choroidal neovascular membrane
}

\author{
Shorya Vardhan Azad, ${ }^{1}$ Brijesh Takkar, ${ }^{1}$ Pradeep Venkatesh, ${ }^{1}$ Atul Kumar ${ }^{2}$
}

${ }^{1}$ Dr Rajendra Prasad Center for Ophthalmic Sciences, All India Institute of Medical Sciences, New Delhi, Delhi, India ${ }^{2}$ Department of Ophthalmology, AllMS, New Delhi, Delhi, India

\section{Correspondence to} Dr Pradeep Venkatesh, venkyprao@gmail.com

Accepted 12 May 2016

\section{DESCRIPTION}

A 16-year-old boy presented with best-corrected visual acuity of $6 / 18$ OD. OS was within normal limits, as was anterior segment OD. A focal whitish-yellow plaque lesion with overlying areas of depigmentation, and retinal atrophy in the central and superior lateral macula were noted in OD. A choroidal neovascular membrane (CNVM) with subretinal haemorrhage was seen at the lesion's inferior medial edge, involving the fovea (figure 1A). Therefore, diagnosis of choroidal osteoma ${ }^{1}$ (CO) was made and confirmed on sonography, with a highly acoustic elevated lesion causing a corresponding shadow (figure 1B).
Fluorescein angiography (FA) confirmed an active CNVM at the medial edge of the osteoma (figure 2A). A lattice-like reflective pattern corresponding to the bony trabeculae ${ }^{2}$ of the tumour in deeper choroid, with overlying area of retinal atrophy and type 1 CNVM was seen on optical coherence tomography (OCT) (figure 2B). Swept-source OCT angiography (SS-OCTA) additionally revealed a superficial lacy network of interconnected new vessels seen in the region of the CNVM, which were thick and dilated (figure 2C). Also, a deeper layer of thin vessels arranged in a 'Medusa head appearance' was seen in the region of the tumour (figure $2 \mathrm{C}, \mathrm{D}$ ). A connection between these groups of vessels could also be deciphered at two junctions (figure 2C).

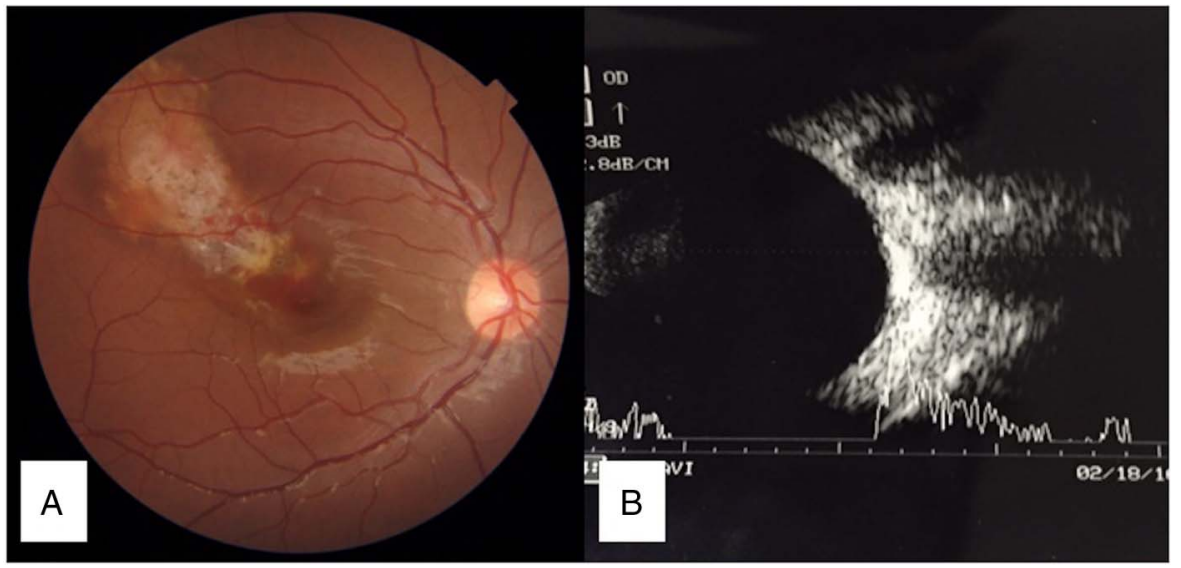

Figure 1 (A) Fundus photograph of the OD showing focal whitish-yellow plaque lesion with overlying area of depigmentation and atrophy. Medial edge of osteoma near fovea shows subretinal haemorrhage with choroidal neovascular membrane. (B) Sonography of the OD showing slightly elevated lesion with high acoustic reflectivity with corresponding shadow giving a false appearance of double optic nerve.

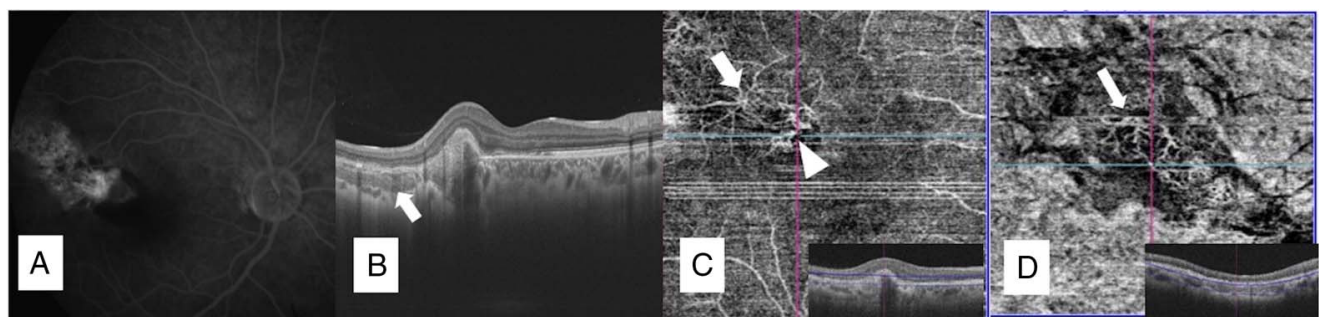

Figure 2 (A) Fluorescein angiography of the OD showing patchy choroidal hyperfluorescence underlying the tumour, with a neovascular membrane at the medial edge of the osteoma. (B) Optical coherence tomography of the OD showing type 1 choroidal neovascular membrane (CNVM). Lattice-work reflectivity is seen corresponding to bone trabeculae (white arrow). (C) Swept-source optical coherence tomography angiograph showing high-resolution superficial network of dilated vessels (white arrowhead) corresponding at the level of CNVM. Tumour vessels in a Medusa head appearance with two visible connections, possibly feeders for CNVM, are also seen (white arrow). (D) Swept-source optical coherence tomography angiograph showing a deeper network of fine thin vessels at the level of the tumour (white arrow). 
Multiple feeder vessels make such CNVMs poor candidates for traditional laser therapy. Findings can be masked in $\mathrm{FA}^{3}$ due to mottled hyperfluorescence related to the CO. SS-OCTA is more informative than standard spectral-domain (SD)-OCTA due to superior image quality.

\section{Learning points}

Swept-source optical coherence tomography angiography (SS-OCTA) additionally reveals high-resolution choroidal vasculature characteristics, which can otherwise get masked due to high tumour density on fluorescein angiography.

- There are multiple connections between the tumour vessels and choroidal neovascular membrane in a case of choroidal osteoma.
Competing interests None declared.

Patient consent Obtained.

Provenance and peer review Not commissioned; externally peer reviewed.

\section{REFERENCES}

1 Mansour AM, Arevalo JF, Al Kahtani E, et al. Role of intravitreal antivascular endothelial growth factor injections for choroidal neovascularization due to choroidal osteoma. J Ophthalmol 2014;2014:210458.

2 Gass JD, Guerry RK, Jack RL, et al. Choroidal osteoma. Arch Ophthalmol 1978;96:428-35.

3 Szelog JT, Bonini Filho MA, Lally DR, et al. Optical coherence tomography angiography for detecting choroidal neovascularization secondary to choroidal osteoma. Ophthalmic Surg Lasers Imaging Retina 2016;47:69-72.

Copyright 2016 BMJ Publishing Group. All rights reserved. For permission to reuse any of this content visit http://group.bmj.com/group/rights-licensing/permissions.

BMJ Case Report Fellows may re-use this article for personal use and teaching without any further permission.

Become a Fellow of BMJ Case Reports today and you can:

- Submit as many cases as you like

- Enjoy fast sympathetic peer review and rapid publication of accepted articles

- Access all the published articles

- Re-use any of the published material for personal use and teaching without further permission

For information on Institutional Fellowships contact consortiasales@bmjgroup.com

Visit casereports.bmj.com for more articles like this and to become a Fellow 